\title{
The Relationship Between Hope and Life Satisfaction Among Children in Low and Middle Socio-Economic Status Communities in Cape Town, South Africa
}

\author{
Claudia Raats $^{1} \cdot$ Sabirah Adams $^{1} \cdot$ Shazly Savahl $^{1}$. \\ Serena Isaacs $^{1} \cdot$ Habib Tiliouine ${ }^{2}$
}

Accepted: 16 March 2018 / Published online: 4 April 2018

(C) Springer Science+Business Media B.V., part of Springer Nature 2018

\begin{abstract}
The overarching aim of the study was to investigate the relationship between hope and life satisfaction among a sample of children in Cape Town, South Africa. More specifically, the study aimed to ascertain the moderating effect of socio-economic status on this relationship. The study uses secondary data from the first wave of the Children's Worlds study. A cross-sectional survey design was employed with the use of stratified random sampling to select a sample of 1004 twelve-year old children attending primary schools within the Cape Town Metropole. The questionnaire administered, incorporated Huebner's (School Psychology International, 12, 231-240, 1991) Students' Life Satisfaction Scale and Snyder et al.'s (Journal of Pediatric Psychology, 22, 399-421, 1997) Children's Hope Scale. Data were analysed by means of correlational analysis, and using the Process Tool for moderation. The results indicate that there is a significant relationship between hope and life satisfaction for both low and middle socio-economic status communities. It was also revealed that socio-economic status
\end{abstract}

Claudia Raats

claudiaraats2@gmail.com

Sabirah Adams

sabirah.adams@gmail.com

Shazly Savahl

ssavahl@uwc.ac.za

Serena Isaacs

sisaacs@uwc.ac.za

Habib Tiliouine

htiliouine@yahoo.fr

1 Department of Psychology, University of the Western Cape, Cape Town, South Africa

2 Laboratory of Educational Processes and Social Context (Labo-PECS), Department of Psychology and Educational Sciences, Oran University, Es Senia, Algeria 
does not moderate the relationship between hope and life satisfaction. It is recommended that further exploration be conducted on the influence of SES on the relationship between hope and life satisfaction. Given that the current study found that SES does not moderate the relationship between hope and life satisfaction, it is recommended that future studies explore the role of SES as a possible mediator.

Keywords Hope · Life Satisfaction · Moderator Effect · Socio-economic Status · Process Tool for Moderation Analysis

\section{Introduction}

The increasing international interest in promoting children's participation in social processes presents the opportunity to engage children in the co-construction of indicators of well-being (Casas 2011). The active involvement of children in measuring and monitoring their own well-being has gained considerable recognition recently, whereas past indicators of child well-being have been based on data collected on children and seldom from children (Bosch et al. 2010; Mason and Hood 2011). Given this, the findings from research with children has led to important insights about what contributes to their well-being and the importance of investigating subjective well-being (SWB) (McAuley, McKeown, and Merriman, 2012; McAuley and Layte, 2012; McAuley and Rose, 2010).

The concept of well-being itself is a broad, contested concept that is widely criticised (Camfield et al. 2008). Its meaning and content thus fluctuates and is dependent on the purpose of the research (Camfield et al. 2008). The great dispute in how well-being should be defined and measured remains contested. Well-being is therefore regarded as a multifaceted construct by most researchers (Forgeard et al. 2011). This includes emotional, social, and functional components. A considerable amount of this discontent is related to the inclusion of these components in a valid theory and measure of wellbeing (Forgeard et al. 2011). As a result of its multifaceted nature, the construct of wellbeing is used synonymously with 'happiness', 'quality of life' and 'life satisfaction' (Forgeard et al. 2011).

Our sense of life satisfaction is reflected in how we perceive our current situation and ultimately, our perceived well-being. Life satisfaction is generally defined as the subjective evaluation of the overall quality of one's life, and is considered to be a key indicator of SWB (Diener and Diener 1995; as cited in Proctor et al. 2009). The allencompassing nature of SWB extends to the experience of pleasant emotions, low levels of negative mood, and high life satisfaction (Diener et al. 2002). Recent empirical evidence shows that life satisfaction is associated with physical health and lower substance abuse, less unemployment and financial strains, a better ability to meet personal standards, optimism/hope, self-efficacy, more social support and less behavioural problems, and higher interpersonal and cognitive functioning (Dolan et al. 2008; Proctor et al. 2009). Family variables such as, family structure, parenting style, parental emotional, social support, and family conflict are considered important in the attainment of life satisfaction among adolescents in particular (Proctor et al. 2009).

Another key dimension of well-being identified in recent literature, is hope (Isaacs and Savahl 2014; Savahl et al. 2013). The concept of hope denotes a 
"positive motivational state that is based on an interactively derived sense of successful agency (goal-directed energy), and pathways (planning to meet goals)", (Snyder 2002, p. 250). Hope, as the provider of agency (Engelbrecht 2011) can therefore be used to improve one's current living conditions, via a process referred to as 'pathways thinking' which holds that our present and imagined futures are linked by thought. Given the significant relationship between hope and well-being amongst children and adolescents, further research is required to unpack the nature and dynamics of this relationship (Savahl et al. 2016). Key to understanding this relationship is examining factors or correlates that influence the relationship. Socio-economic status (SES) has long been regarded as one these critical factors influencing both hope and SWB.

The relationship between SWB and socio-economic status is a complex one. Although this relationship remains positive, it does not necessarily mean that individuals from the highest SES group will in fact report greater levels of SWB (Pavot and Diener 2013). Diener et al. (1985) found that more than one-third of wealthy individuals reported below average SWB. This finding can be attributed to the argument that a rise in income is accompanied by a rise in material living standards (Pavot and Diener 2013). This proposes that SWB only increases slightly above the average reported SWB by means of a considerable rise in income, where it will then decrease as SES further increases. This resonates with the Easterlin (1974) paradox, which essentially holds that income differences are generally positively correlated with SWB, with little or no corresponding increases in SWB when national SES increases (Pavot and Diener 2013). Further evidence suggests that although SWB levels decreases as SES increase above the average set point, the correlation between income and SWB remains strongest for individuals living in poverty or near-poverty (that is for individuals living on and below the average SES), (Diener et al. 2008). Easterlin's (1974) original hypothesis has, however, not fully been supported by the literature, with researchers such as Stevenson and Wolfers (2008) finding that increases in GDP is associated with consistent increases in life satisfaction. Recently, further analysis conducted by Easterlin (2013) found that within countries, wealthier people have a higher level of life satisfaction than poorer people, but that this is only relevant for relative income and not absolute income (Adler and Seligman 2016).

Research has found that SES is related to children and adolescents' health, cognitive and educational attainment, socio-emotional development, and access to resources (Bradley and Corwyn 2002). The relationship between SES, SWB and hope amongst children and adolescents has also recently received empirical consideration. Savahl et al. (2016), in their validation of the Children's Hope Scale on a sample of children from three SES groups (low, lower-middle, and upper-middle) in Cape Town, found that hope was comparable across SES groups. They further found that there was a significant difference between SES groups, with the lower-middle and upper-middle SES groups scoring significantly higher than the low SES group. Further studies on children's SWB conducted in Cape Town by Savahl et al. (2017a, 2017b) across two SES communities, found no significant difference in life satisfaction between low and middle SES groups. Noting the contestation within the literature, the current study looks at the extent to which SES could moderate the relationship between hope and life satisfaction 
within a South African context, for both low and middle SES communities. In South Africa SES is brought into stark focus given the high level of social inequality. With a Gini Index of .63 (Bosch et al. 2010), considered to be one of the highest in the world (in terms of wealth and income), it demonstrates a great dispersion of both wealth and income between the privileged and the disadvantaged. Although this inequality is experienced by the majority of the population, the burdens of these "multiple overlapping layers of inequality' are often endured by children who necessitate care and supervision from adults for their protection and well-being" (Hall et al. 2012, p. 24). An exploration of the impact of SES and social inequality is incomplete without consideration of the oppressive backdrop of Apartheid. Based on a philosophy of socio-economic exclusion and segregation the Apartheid legislative framework dominated the socio-political landscape of South Africa for nearly five decades. Characterised by institutionalised racism and systematic economic oppression, Apartheid resulted in a significant proportion of the population being disenfranchised, denied access to resources, land, education opportunities, and basic human rights (Savahl et al. 2016).

One of the most devastating legacies of Apartheid is the extreme levels of social inequality experienced by various cohorts of the population, manifesting in the polarisation of communities and neighbourhoods into privileged or middle SES and disadvantaged or lower SES communities. Privileged communities are characterised by high income, educational attainment and employment. Disadvantaged communities are characterised by low educational attainment and income, high rates of substance abuse, unemployment, crime and violence (Savahl et al. 2015). Located between the high and low extremes a cohort presenting with a mid-level socio-economic status is identifiable. This population cohort mainly consists of individuals who were previously advantaged by the Apartheid regime, and those that have managed intergroup mobility since the attainment of democracy in 1994. Typically, the latter cohort is characterised as the emerging middle class and consists of previously disadvantaged individuals who through policy change, education, resilience and other positive psychological traits managed to achieve a sustainable level of economic security (Adams and Savahl 2017; Savahl et al. 2016).

Overall, while the literature has established a clear relationship between hope and life satisfaction, the extent to which this relationship is influenced by SES is less clear. The overarching aim of the study was to ascertain the nature of the relationship between hope and life satisfaction among children in both low and middle SES communities in Cape Town. Furthermore, the study aims to determine the extent to which SES moderates the relationship between hope and life satisfaction. According to Baron and Kenny's (1986) classic text, a moderator variable is a third variable that "affects the direction and/or strength of the relation between an independent or predictor variable and a dependent or criterion variable" (p. 1174).

The following hypotheses have been developed to guide the study:

Hypothesis 1: There is a significant positive relationship between hope and life satisfaction in low socio-economic status communities

Hypothesis 2: There is a significant positive relationship between hope and life satisfaction in middle socio-economic status communities

Hypothesis 3: The relationship between hope and life satisfaction for the low and middle socio- economic status communities is moderated by socio-economic status 


\section{Method}

\subsection{Research Design}

The study uses the first wave of the South African data of the Children's Worlds study. The study aims to collect data on children's lives and daily activities, the manner in which they utilize their time and their perceptions and evaluations of their personal well-being. The study therefore hopes to raise awareness of children's well-being and their life situations, in order to influence government policies and services (see isciweb. org ).

The current study focused on specific aspects within the Children's World's study, more specifically, on the measurement of hope and life satisfaction, with the manifestation of SES as a moderator variable. This study followed a quantitative methodological framework and used a cross-sectional, correlation design.

\subsection{Research Context}

As previously mentioned, South Africa has a highly skewed distribution of wealth and income between the privileged and the disadvantaged (World Bank 2012). This widespread social inequality is among the most detrimental consequences of the Apartheid regime in the country. Children, in particular those living in low SES communities, are negatively affected by the disparate levels of household income (Hall et al. 2012). The child population in South Africa is 18.6 million, representing $37 \%$ of the total population. Of this total, $45 \%$ are between the ages of 10-17 years old, with a gender composition of $49 \%$ female, and $51 \%$ male. National estimates indicate that $54.6 \%$ of the child population live in urban areas, while $45.4 \%$ live in rural areas. In the Western Cape, however, the majority of children (94.6\%) live in urban areas, while a small proportion (5.4\%) lives in rural areas (Hall et al. 2012).

The research for the larger study was conducted in the Western Cape Metropole which is one of nine provincial regions in South Africa. It is a typical urban environment with a population of an estimated 6 million of which 1636000 are children (Statistics South Africa, 2015). The participants in the current study were selected from primary schools in both low and middle SES communities in the Western Cape.

\subsection{Participants}

The sampling frame for the study included 12-year-old children attending primary schools within the four Education Management District Councils (EMDC's) of the Western Cape Education Department (WCED) Metropole. A two-stage stratified random sampling protocol was followed, ensuring that children from various cultural, SES, and geographical groups were selected. In the first stage schools were stratified according to their location within the EMDC's. Thereafter, schools were stratified by SES (low and middle) and randomly selected from these strata. Schools located in previously disadvantaged communities and those designated as Section 21 schools (no fees schools) were classified as low SES schools. Schools classified as middle SES schools, were those located in privileged communities (characterised by high: income, 
educational attainment, levels of employment, and low incidence of violence) with an annual school fee of equal to or more than R5000 per learner. While it was envisaged to obtain an equal number of schools from low and middle SES communities, the final sample consisted of eight schools from low SES and seven schools from middle SES communities. All the 12-year-old children in the schools were selected to participate. The final sample consisted of 1004 participants, distributed as follow: $46.1 \%$ males, $53.9 \%$ females, $58.6 \%$ low SES and $41.4 \%$ middle SES participants.

\subsection{Measures}

The survey instrument, originally developed in English and Spanish, was adapted to the South African context. Firstly, the questionnaire underwent a process of cognitive testing, including two focus groups consisting of 10 children each. These participants were purposively selected from primary schools within the sampling frame. This process essentially aided in the phrasing, refining, and modification of items in the questionnaire. Subsequently, the revised questionnaire was back- translated into Afrikaans (second process), of which both versions (English and Afrikaans) were then piloted (third process) with a sample of 100 twelve-year-old children, randomly selected from low and middle SES schools. The final process assisted with the ordering and sequencing of items, as well as the length of the questionnaire, in support of finalizing the survey instrument.

A number of internationally validated scales were included in the questionnaire. These included the Students' Life Satisfaction Scale (Huebner 1991), and the Children's Hope Scale (Snyder et al. 1997).

\subsubsection{Children's Hope Scale}

The Children's Hope Scale (CHS) is a 6-item scale with responses ranging from $1=$ none of the time, to $6=$ all of the time (Snyder 1995; Marque, Pais-Robeiro, and Lopez, 2011). This 6-point Likert -type self-report measure (Snyder 1995) is based on Snyder's Hope Theory (Snyder et al. 1997). Possible scores range from 6 to 36, with high scores denoting higher levels of hope (Marque et al., 2011). This measure was developed and validated for use with children aged 7 to 16 years (Lopez et al. 2000). Three of the items contain questions evaluating 'pathways thinking' (e.g. I can think of many ways to get the things in life that are most important to me), as well as, three questions that examine 'agentic thinking' (e.g. I am doing just as well as other kids of my age), (Marque et al., 2011). This scale has produced the following acceptable psychometric properties: (a) internal consistencies with Cronbach alpha's ranging from .72 to .86; (b) test-retest reliabilities of .71 to .73 over one month; and (c) convergent and discriminant validities (Lopez et al. 2009). The scale has previously been validated on samples of children in Cape Town across low, lower-middle, and upper-middle SES groups (see Savahl et al. 2016).

\subsubsection{Students' Life Satisfaction Scale}

The Students' Life Satisfaction Scale (SLSS) is a 7-item measure of global life satisfaction, developed and validated for use with children aged 8-18 (Huebner 1991). Respondents are asked to answer the questions based on the thoughts they had in the last few weeks and requires respondents to rate their satisfaction with respect to items that are domain-free 
(Huebner et al. 2004). Six response choices exist, which are presented as an affirmation and range from $1=$ strongly disagree to $6=$ strongly agree (Huebner 1991). Scores range from 7 to 42 , with the higher scores denoting higher levels of global satisfaction with life (Huebner 1991). The measure reports an internal consistency of .82 and an adequate twoweek test-retest reliability of .74, (Huebner 1991). The SLSS has also shown good crosscultural adaptation with children aged 8-18 years across a range of contexts (see e.g. Casas et al. 2014; Jones 2011; Savahl et al. 2017a, 2017b). Recently Savahl et al. (2017a, 2017b) validated the scale for use on children across low and middle SES groups in Cape Town. Their results indicated a good-fit structure for the overall scale, and that metric and scalar invariance was tenable across socio-economic status groups. Importantly the authors noted low standardised regression weights for the two negatively phrased items on the SLSS, which substantially affected the structural validity of the scale. They recommend that these items be removed when working with samples of children from South Africa. Recent research conducted by Casas and Rees (2015) similarly caution against including the negatively phrased items. The current study therefore used a 5-item version of the SLSS with 5-point verbal response options ranging from strongly disagree to strongly agree.

\subsection{Procedure and Ethics}

Permission to conduct the study was obtained from the Senate Research Ethics Committee of the University of the Western Cape, as well as the Western Cape Education Department (WCED). An information session was arranged with the school principals and the 12-yearold children in the selected schools where the aim, the nature of their involvement and ethics of the study were discussed. The participants were advised on the ethics principles of informed consent, confidentiality, the right to withdraw, and privacy. Those who agreed to participate were requested to provide signed consent, as well as obtain signed consent from their parents. Only those who returned the consent forms participated in the study. The questionnaires were administered following a researcher-administered protocol.

\subsection{Data Analysis}

The IBM Statistical Package for the Social Sciences (IBM SPSS v.22) software was used to analyse the data. The Pearson Product-Moment Correlational analysis was used to explore the relationship between hope and life satisfaction. Hayes Process tool for moderation analysis (referring to the analysis of a third variable which influences the relationship between a dependent and an independent variable), was used to determine whether the relationship between hope and life satisfaction was moderated by SES. This tool determined the extent to which SES exerts an influence on the relationship between hope and life satisfaction (Field 2013).

\section{Results}

The study aimed to investigate the relationship between hope and life satisfaction among children in both low and middle SES communities, by utilizing the CHS and SLSS. For this sample a Cronbach's alpha of .81 was found for the CHS and .82 for the SLSS. Table 1 presents the overall mean scores for the CHS and the SLSS. The results 
Table 1 Overall SLSS and hope means by SES

\begin{tabular}{|c|c|c|c|c|c|c|c|c|c|}
\hline & \multicolumn{3}{|c|}{ Low SES } & \multicolumn{3}{|c|}{ Middle SES } & \multicolumn{3}{|l|}{ Total } \\
\hline & $\mathrm{N}$ & Mean & SD & $\mathrm{N}$ & Mean & SD & $\mathrm{N}$ & Mean & SD \\
\hline SLSS & 589 & 2.99 & 0.85 & 415 & 2.96 & 0.78 & 1004 & 2.98 & 0.82 \\
\hline HOPE & 589 & 4.59 & 1.05 & 415 & 4.60 & 1.01 & 1004 & 4.60 & 1.03 \\
\hline
\end{tabular}

The overall mean scores for the SLSS indicates similar scores for the low and middle SES groups (Low SES: Mean $=2.99 ; \mathrm{SD}=0.85 ;$ Middle SES: Mean $=2.96 ; \mathrm{SD}=0.78$ )

*The SLSS was scored from 0 to 4 , with scores closer to 4 indicating higher life satisfaction

*The SLSS was scored from 1 to 6 , with scores closer to 6 indicating higher levels of hope

showed no significant mean differences among SES communities with regard to hope and life satisfaction.

\subsection{Correlation Analysis}

Hypothesis 1: There is a significant relationship between hope and life satisfaction in low socio-economic status communities

A Pearson Correlation analysis was used to determine the relationship between hope and life satisfaction for the low SES group. A positive, moderate relationship was found $(r=.54$, $p<.001)$ indicating that an increase in the level of hope is associated with a significant increase in satisfaction with life (see Table 2). The hypothesis is therefore accepted.

Hypothesis 2: There is a significant relationship between hope and life satisfaction in middle socio-economic status communities.

A Pearson Correlation analysis was used to determine the relationship between hope and life satisfaction for the middle SES group. A positive, moderate relationship was found $(r=.59, p<.001)$ indicating that an increase in the level of hope is associated with a significant increase in satisfaction with life (see Table 2). The hypothesis is therefore accepted.

Table 2 Correlation between hope and life satisfaction by SES

\begin{tabular}{|c|c|c|c|c|}
\hline & & & Life satisfaction & Hope \\
\hline \multirow[t]{3}{*}{ Low-SES group } & \multirow[t]{3}{*}{ Life satisfaction } & Pearson correlation & 1 & $.542^{*}$ \\
\hline & & Sig. (2-tailed) & & .000 \\
\hline & & $\mathrm{N}$ & 589 & 589 \\
\hline \multirow[t]{3}{*}{ Middle-SES group } & \multirow[t]{3}{*}{ Life satisfaction } & Pearson correlation & 1 & $.591^{*}$ \\
\hline & & Sig. (2-tailed) & & .000 \\
\hline & & $\mathrm{N}$ & 415 & 415 \\
\hline
\end{tabular}

$* p<.001$ 


\subsection{Moderation Analysis}

Hypothesis 3: The relationship between hope and life satisfaction for the low and middle socio economic status communities is moderated by socio-economic status.

Hayes Process Tool for Moderation Analysis (Field 2013) was used to determine whether SES has a moderating effect on the relationship between hope and life satisfaction (see Table 3). In the current model, moderation is not present as the interaction Hope and Life Satisfaction by SES is not significant $(t=.42, p>.05)$. However, hope $(t=21.70, p<.001)$ was found to be a significant predictor of children's life satisfaction, while SES $(t=-0.71, p>.05)$ is not a significant predictor of children's life satisfaction. Hope and SES account for $31.46 \%$ of the variation in Life Satisfaction $(F=157.97, p<.001)$. The model is thus a significant fit to the data. The moderation analysis was followed-up with a simple slopes analysis displayed in Fig. 1. The null hypothesis is therefore retained.

The simple slopes analysis shows a positive relationship between hope and life satisfaction for both SES groups. However, while Fig. 1 shows that the relationship is stronger for the low SES group than for the middle SES group, it is not significantly stronger.

\section{Discussion}

\subsection{The Relationship Between Hope and Life Satisfaction}

The current study found a significant positive relationship between hope and life satisfaction among children in Cape Town. This finding is in line with the findings in recent literature (see Gilman and Huebner 2006; Park and Peterson 2006; Savahl et al. 2013), who identified hope as a character strength, being positively associated with life satisfaction.

The majority of participants indicated on the SLSS that they are, generally, satisfied with their lives. This means that they are at minimal risk of experiencing negative outcomes such as mental and physical health problems (see Frisch 2000, for a review), and more open to the experience of positive outcomes in their intrapersonal, interpersonal, vocational, health, and educational arenas (Lyubormirsky, King, and Diener, 2005). Ultimately this means that participants are guided by positive affect and the tendency to evaluate their lives as satisfactory.

Table 3 Linear model of predictors of life satisfaction

\begin{tabular}{lllll}
\hline & $\mathrm{b}$ & $\mathrm{SE} \mathrm{B}$ & $\mathrm{t}$ & $\mathrm{p}$ \\
\hline Constant & $14.88[14.67,15.09]$ & .11 & 138.69 & $<.001$ \\
SES (centred) & $-0.15[-0.57,0.27]$ & .21 & -0.71 & $>.05$ \\
Hope (centred) & $0.37[.34, .40]$ & .02 & 21.70 & $<.001$ \\
SES x Hope & $0.01[-.05,-.08]$ & .03 & 0.42 & $>.05$ \\
\hline
\end{tabular}

$R^{2}=.31$ 


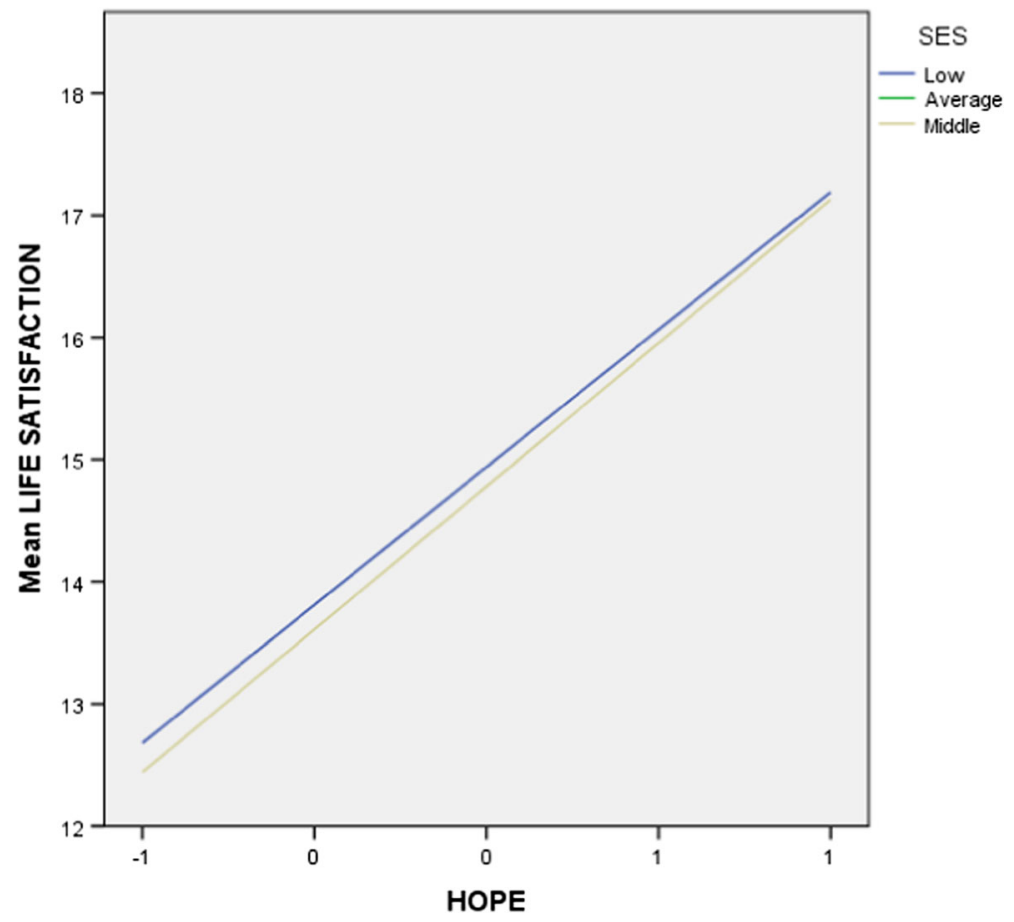

Fig. 1 Simples slopes analysis

Participants from both low and middle SES communities generally seem to experience a high sense of hope. This finding could be explained as participants perceiving themselves as being able to reach their desired goals and as a result, are not at risk for negative psychological outcomes, caused by repeated goal blockages and unsuccessful attempts, which might exacerbate the symptoms for adverse psychological outcomes (Snyder 1994). Their account of their sense of hope is associated with a level of personal control (Norwicki and Strickland, 1973). Similarly, Huebner (1991) points to the internal locus of control as being among the strongest correlates of life satisfaction for children aged 10 to 13 . Accordingly, the two core aspects measured by the CHS are successful agency and pathways, thus placing the emphasis on the child to direct his or her life. These aspects are vital in the learning of school information which is facilitated by children's capacities to form goals and to use pathways effectively, in order to pursue those goals.

\subsection{Socio-Economic Status as a Moderator in The Relationship Between Hope and Life Satisfaction}

The impact of SES, specifically with reference to the availability of resources, is regarded as a significant factor in individuals' pursuit of their goals and may have an impact on their hope and life satisfaction (Merkaš and Brajša-Žganec, 2011). However, a key finding of the current study is that SES does not moderate the relationship between hope and life satisfaction. While there is evidence that individuals from higher SES groups will be more satisfied with their lives and experience a greater sense of 
hope, than their those from lower SES groups (Peiró 2006; Headey et al. 2008; Savahl et al. 2016), others such as (Snyder 1994) found no relationship between family income and children's level of hope. To some extent this can be attributed to children from low SES communities receiving the necessary, yet sufficient, care and attention from their caregivers, interacting with positive role models and high levels of religiosity, which result in the elevation of the levels of hope (Isaacs and Savahl 2014). Furthermore, Savahl et al. (2016), commenting on research conducted among children across various SES groups in Cape Town, state that it is possibly less about the actual level of SES, but rather the level of social inequality that plays a crucial role in young people's level of hope and how it interacts with subjective well-being (SWB).

A further explanation of the finding in the current study can be found in Forgeard et al. (2011) assertion that life satisfaction judgments depend on the standards participants have set for themselves; hence participants with similar objective circumstances may judge their lives to be more or less satisfying. Similarly, van Praag (2011) argues that well-being varies according to the reference group, person or social type that individuals compare themselves to. Therefore, comparisons to reference groups affect the feelings of an individual's SWB (Van Praag 2011). It is likely that participants in the current study did not evaluate their lives in relation to other participants who live in different or better circumstances.

While low SES communities in Cape Town are typically characterized by poverty, crime and violence, and limited resources, hope may serve as a protective factor (Isaacs and Savahl 2014). There is evidence that having a sense of hope may play a more important role in children's perception of life satisfaction than their objective living conditions and may even be more important than the financial difficulties invariably experienced by low SES households (Bronk et al. 2009). Therefore, it is this purpose to change many things in their lives that in turn, elevates their sense of life satisfaction (Bronk et al. 2009). This may imply that subjective indicators of hope are more likely to play a critical role in participants' assessment of their life satisfaction, than the objective indicator of SES (Van Praag 2011). Moreover, SES predicts SWB only if it is related to children's goals (Merkaš and Brajša-Žganec, 2011).

\section{Conclusion}

The positive association between hope and life satisfaction implies that children are experiencing positive outcomes in various areas of their lives and that they are better able to control the impact of stressful life events. It is also important to note that children of this age are generally regarded as having a heightened sense of hope and a positive sense of life satisfaction. This is motivated in terms of where children find themselves cognitively, naturally progressing and experiencing optimal human development, without the differentiation between children from low SES communities and those from middle SES communities. Hope, in essence, seems to have a more pronounced impact on children's life satisfaction.

This study presents with a few limitations. Firstly, it is restricted in its generalizability, as the sample was composed of participants from only one age group, thus data are not comparable across the age spectrum. Secondly, the cross-sectional design of this study only provides a snapshot of participant's well-being at the present time and as 
such, should a longitudinal study be conducted there might be a variation in the results. Furthermore, having participants approach the transitioning phase from primary to high school, may have contributed to participants reporting a greater sense of life satisfaction than what they are actually experiencing. The SLSS provides an overall account of one's life satisfaction and so it does not provide insight into life satisfaction across various domains (such as satisfaction with family, friends and school) that are of interest to children and youth (Huebner and Gilman 2003).

In order to obtain a more differentiated picture of the well-being of children, a multidimensional measure would be useful in assessing life satisfaction across multiple domains of interest to children (Huebner and Gilman 2003). It is evident from the literature, that there is a lack of research investigating the relationship between hope and life satisfaction among children and adolescents within the South African context. Hence, future research in this field is required. This kind of research should be conducted on a sample that is representative across age groups, across geographical locations, as well as SES groups.

Finally, it is recommended that further exploration be conducted on the influence of SES on the relationship between hope and life satisfaction. Given that the current study found that SES does not moderate the relationship between hope and life satisfaction, it is recommended that future studies explore the role of SES as a possible mediator. In this way the role of SES as a potential mechanism through which hope can influence and produce changes in SWB can be observed.

Acknowledgments The authors would herewith like to acknowledge the Jacobs Foundation for institutional and financial support.

\section{References}

Adams, S., \& Savahl, S. (2017). Children's Discourses of Natural Spaces: Considerations for children's Subjective Well-Being. Child Indicators Research, 10(2), 423-446.

Adler, A., \& Seligman, M. E. (2016). Using wellbeing for public policy: Theory, measurement, and recommendations. International Journal of Wellbeing, 6(1).

Baron, R. M., \& Kenny, D. A. (1986). The Moderator-Mediator Variable Distinction in Social Psychological Research: Conceptual, Strategic, and Statistical Considerations. Journal of Personality and Social Psychology, 51(6), 1173-1182.

Bosch, A., Roussouw, J., Claassens, T., \& du Plessis, B. (2010). A Second Look at Measuring Inequality in South Africa: A Modified Gini Coefficient. School of Development Studies, Working paper (58). University of Kwazulu-Natal.

Bradley, R. H., \& Corwyn, R. F. (2002). Socioeconomic status and child development. Annual Review of Psychology, 53(1), 371-399.

Bronk, K. C., Hill, P. L., Lapsley, D. K., Talib, T. L., \& Finch, H. (2009). Purpose, hope, and life satisfaction in three age groups. Journal of Positive Psychology: Dedicated to furthering research and promoting good practice, 4(6), 500-510.

Camfield, L., Streuli, N., \& Woodhead, M. (2008). Children's Well-being in Contexts of Poverty: Approaches to Research, Monitoring and Participation. Young Lives, 12, 1-27.

Casas, F. (2011). Subjective social indicators and child and adolescent well-being. Child Indicators Research, $4(4), 555-575$.

Casas, F., \& Rees, G. (2015). Measures of children's subjective well-being: analysis of the potential for cross national-comparisons. Child Indicators Research, 8(1), 49-69. 
Casas, F., Tiliouine, H., \& Figuer, C. (2014). The Subjective Well-being of Adolescents from Two Different Cultures: Applying Three Versions of the PWI in Algeria and Spain. Social Indicators Research, 115, 637-651.

Diener, E., \& Diener, M. (1995). Cross-cultural correlates of life satisfaction and self-esteem. Journal of Personality and Social Psychology, 68, 653-663.

Diener, E., Horwitz, J., \& Emmons, R. A. (1985). Happiness of the very wealthy. Social Indicators Research, 16(3), 263-274.

Diener, E., Lucas, R. E., \& Oishi, S. (2002). Subjective well-being. Handbook of positive psychology, 63-73.

Diener, E., Ng, W., \& Tov, W. (2008). Balance in life and declining marginal utility of diverse resources. Applied Research in Quality of Life, 3(4), 277-291.

Dolan, P., Peasgood, T., \& White, M. (2008). Do we really know what makes us happy? A review of the economic literature on the factors associated with subjective well-being. Journal of Economic Psychology, 29, 94-122.

Easterlin, R. A. (1974). Does economic growth improve the human lot? Some empirical evidence. Nations and households in economic growth, 89, 89-125.

Easterlin, R. A. (2013). Happiness, growth, and public policy. Economic Inquiry, 51(1), 1-15.

Engelbrecht, G. J. (2011). The performance of hope: The social construction of self-stories embedded in Godstories in the context of a short-term rehabilitation programme for addiction. Submitted in accordance with the requirements for the degree of Doctor in Theology: University of South Africa.

Field, A. (2013). Discovering statistics using IBM SPSS statistics $\left(4^{\text {th }} . e d\right)$. Los Angeles: Sage Publications.

Forgeard, M. J., Jayawickreme, E., Kern, M. L., \& Seligman, M. E. (2011). Doing the right thing: Measuring wellbeing for public policy. International Journal of Wellbeing, 1(1), 79-106.

Frisch, M. B. (2000). Improving mental and physical health care through quality of life therapy and assessment. In E. Diener \& D. R. Rahtz (Eds.), Advances in quality of life theory and research (pp. 207-241). Dordrecht, Netherlands: Kluwer Academic Press.

Gilman, R., \& Huebner, E. S. (2006). Characteristics of adolescents who report very high life satisfaction. Journal of Youth and Adolescence, 35, 311-319.

Hall, K., Woolard, I., Lake, L., \& Smith, C. (2012). Children and inequality: Closing the gap. South African Child Gauge. Cape Town: Children's Institute.

Headey, B., Muffels, R., \& Wooden, M. (2008). Money does not buy happiness: or does it? A re-assessment based on the combined effects of wealth, income and consumption. Social Indicators Research, 87, 65-82.

Huebner, E. S. (1991). Initial development of the Students' Life Satisfaction Scale. School Psychology International, 12, 231-240.

Huebner, E. S., \& Gilman, R. (2003). Toward a focus on positive psychology in school psychology. School Psychology Quarterly, 18(2), 99-102.

Huebner, E. S., Suldo, S. M., Smith, L. C., \& McKnight, C. G. (2004). Life satisfaction in children and youth: Empirical foundations and implications for school psychologists. Psychology in the Schools, 41, 81-93.

Isaacs, S. A., \& Savahl, S. (2014). A qualitative inquiry investigating adolescents' sense of hope within a context of violence in a disadvantaged community in Cape Town. Journal of Youth Studies, 17(2), 269278.

Jones, J. L. (2011). Adolescent well-being in West Africa: Subjective well-being of adolescents in Cote d'Ivoire. Tulane University, Louisiana, United States of America: Unpublished doctoral dissertation.

Lopez, S. J., Ciarlelli, R., Coffman, L., Stone, M., \& Wyatt, L. (2000). Diagnosing for strengths: On measuring hope building blocks. In C. R. Snyder (Ed.), Handbook of hope: Theory, measures, and interventions (pp. 57-85). San Diego: Academic Press.

Lopez, S. J., Rose, S., Robinson, C., Marques, S., \& Pais Reibero, J. (2009). Measuring and promoting hope in schoolchildren. In R. Gilman, E. S. Huebner, \& M. Furlong (Eds.), Promoting wellness in children and youth: Handbook of positive psychology in the schools (pp. 37-51). Mahwah, New Jersey: Lawrence Erlbaum.

Lyubomirsky, S., King, L., Diener, E. (2005). The Benefits of Frequent Positive Affect: Does Happiness Lead to Success? Psychological Bulletin, 131(6), 803-855.

McAuley, C., McKeown, C., Merriman, B. (2012). Spending time with family and friends: children's views on relationships and shared activities. Child Indicators Research, 5(3), 449-467.

Marques, S.C., Pais-Ribeiro, J.L., Lopez, S.J. (2011). The role of positive psychology constructs in predicting mental health and academic achievement in children and adolescents: A two-year longitudinal study. Journal of Happiness Studies, 12(6), 1049-1062. https://doi.org/10.1007/s10902-010-9244-4.

Mason, J., \& Hood, S. (2011). Exploring Issues of Children and Actors in Social Research. Children and Youth Services Review, 33(4), 490-495. 
Merkaš, M., \& Brajša-Žganec, A. (2011). Children with different levels of hope: Are there differences in their self-esteem, life satisfaction, social support, and family cohesion? Child Indicators Research, 4, 499-514.

Nowicki Jr. S., \& Strickland, B.R. (1973). A locus of control scale for children. Journal of Consulting and Clinical Psychology, 40, 148-154.

Park, N., \& Peterson, C. (2006). Character strengths and happiness among young children: Content analysis of parental descriptions. Journal of Happiness Studies, 7, 323-341.

Pavot, W., \& Diener, E. (2013). Happiness experienced: The science of subjective well- being. Oxford handbook of happiness, 134.

Peiró, A. (2006). Happiness, satisfaction and socio-economic conditions: some international evidence. Journal of Socio-Economics, 35, 348-365.

Proctor, C. L., Linley, P. A., \& Maltby, J. (2009). Youth life satisfaction: A review of the literature. Journal of Happiness Studies, 10, 583-630.

Savahl, S., Isaacs, S., Adams, S., Carels, C. Z., \& September, R. (2013). An exploration into the impact if exposure to community violence and hope on children's perceptions of well-being: A South African Perspective. Child Indicators Research, 6(3), 579-592.

Savahl, S., Adams, S., Isaacs, S., September, R. L., Hendricks, G., \& Noordien, Z. (2015). Subjective wellbeing amongst a sample of children in the Western Cape region of South Africa: A descriptive study. Child Indicators Research, 8(1), 211-226.

Savahl, S., Casas, F., \& Adams, S. (2016). Validation of the Children's Hope Scale amongst a sample of adolescents in the Western Cape region of South Africa. Child Indicators Research, 9(3), 701-713.

Savahl, S., Casas, F., \& Adams, S. (2017a). Children's subjective well-being: Multi-group analysis among a sample of children from two socio-economic status groups in the Western Cape, South Africa. Child Indicators Research, 10(2), 473-488.

Savahl, S., Tiliouine, H., Casas, F., Adams, S., Mekonen, Y., Dejene, N., Benninger, E., \& Witten, H. (2017b). Children's subjective well-being in Africa: A comparative analysis across three countries. Children and Youth Services Review, 80, 31-40.

Snyder, C. R. (1994). The psychology of hope: You can get there from here. New York: Simon \& Schuster Inc..

Snyder, C. R. (1995). Conceptualizing, measuring, and nurturing hope. Journal of Counselling and Development, 73, 355-360.

Snyder, C. R. (2002). Hope theory: Rainbows in the mind. Psychological Inquiry, 13, 249-275.

Snyder, C. R., Hoza, B., Pelham, W. E., Rapoff, M., Ware, L., Danovsky, M., \& Stahl, K. J. (1997). The development and validation of the Children's Hope Scale. Journal of Pediatric Psychology, 22(3), 399421.

Statistics South Africa (2015). General Household Survey. Statistics South Africa: Pretoria.

Stevenson, B., \& Wolfers, J. (2008). Economic growth and subjective well-being: Reassessing the Easterlin paradox (No. w14282). National Bureau of Economic Research.

Van Praag, B. (2011). Well-being inequality and reference groups: an agenda for new research. The Journal of Economic Inequality, 9(1), 111-127.

World Bank. (2012). Annual Report 2012. World Bank. 